\title{
PENGARUH KOMUNIKASI DALAM KEHIDUPAN PERSPEKTIF AL-QURAN DAN HADIS
}

\author{
Harjani Hefni
}

\begin{abstract}
Abstrak
Komunikasi antar manusia merupakan aktivitas menyampaikan dan menerima pesan dari dan kepada orang lain. Saat berlangsung komunikasi, proses pengaruh mempengaruhi terjadi. Di samping itu, komunikasi juga bertujuan untuk saling mengenal, berhubungan, bermain, saling membantu, berbagi informasi, mengembangkan gagasan, memecahkan masalah, meningkatkan produktivitas, membangkitkan semangat kerja, meyakinkan, menghibur, mengukuhkan status, membius, dan menciptakan rasa persatuan. Di samping tujuan baik tersebut, komunikasi juga dapat dipakai untuk saling mendomba, melemahkan semangat, meruntuhkan status, membuat orang sedih, dan membuat orang terjerumus ke dunia hitam. Islam memberikan arah agar komunikasi manusia berkualitas dan konstruktif bukan sebaliknya.
\end{abstract}

Kata Kunci : pemahaman, metode, hubungan

\section{A. Pendahuluan}

Komunikasi didefinisikan secara sederhana sebagai proses pernyataan antarmanusia. ${ }^{1}$ Cara menyatakan dan mengungkapkan pesan sangat beragam. Ide yang terdapat dalam diri kita dituangkan lewat media lisan atau tulisan (qalam) . Allah menyebut proses pernyataan antarmanusia itu dengan istilah 'bayan' dan menyebutnya sebagai

\footnotetext{
1 Onong Uchjana Effendi, IImu, Teori dan Filsafat Komunikasi (Jakarta, PT.Citra Aditya Bakti, 2003), h.28
}

bagian dari kasih sayang-Nya yang terbesar bagi umat manusia. ${ }^{2}$

Dalam perspektif Islam, potensi berkomunikasi pada manusia merupakan pemberian Allah yang sudah otomatis ada sejak dia diciptakan. ${ }^{3}$ Setelah unsur jasad dan ruh berpadu dalam dirinya di hari ke-120 ${ }^{4}$,manusia kecil yang sedang

\footnotetext{
2 Dalam Surat ar-Rahman ayat 4, Allah menyebutkan bahwa di antara bentuk kasih sayang-Nya kepada manusia adalah dengan mengajarkan kepada mereka 'bayan'.

${ }^{3}$ Allah berfirman: "Tuhan Yang Maha Pemurah, Yang telah mengajarkan Alquran, Dia menciptakan manusia, mengajarkan pandai berbicara". (QS. Al-Rahmān : 1-4)

4 Dalam sebuah hadis disebutkan "Sesungguhnya kalian diciptakan di perut ibunya empat puluh hari fase 'nutfah', kemudian fase
} 
tumbuh dalam rahim ibunya itu sudah mulai mampu berkomunikasi dengan alam di luar rahim. Alquran mengisyaratkan bahwa alat komunikasi yang paling pertama berfungsi pada manusia adalah pendengaran. ${ }^{5}$

Isyarat Alquran tentang berfungsinya pendengaran sejak dalam kandungan diperkuat oleh penelitianpenelitian modern.

"Laitner (1987) melaporkan bahwa di Hayward, California, Dr.Rene Van de Carr, seorang ahli kandungan dan kebidanan, mendirikan Universitas Prenatal (UP). Kegiatannya meliputi pengajaran terhadap bayi yang masih dalam rahim : melatih kemampuan verbalnya dan kemampuan bersosialisasinya lebih dini. Orang tua bercakap-cakap dengan bayinya melalui megafon kertas (disebut pregafon) yang diarahkan ke perut ibunya. Penelitian terhadap 'Iulusan-Iulusan' UP menunjukkan bahwa mereka mampu berkomunikasi lebih awal, mampu merangkaikan kata-kata lebih dini, dan

'alaqah' juga 40 hari, kemudian fase 'mudghah' 40 hari, dan setelah itulah ruh diciptakan..." (HR.Bukhari, no.2969, dan Muslim no.4781)

5 Allah berfirman:9. "Kemudian Dia menyempurnakan dan meniupkan ke dalamnya roh (ciptaan)-Nya dan Dia menjadikan bagi kamu pendengaran, penglihatan dan hati; (tetapi) kamu sedikit sekali bersyukur. para ibu merasa bahwa si anak lebih cepat memahami sesuatu". ${ }^{6}$

\section{B. Pengaruh Komunikasi Pada Manusia}

Proses pernyataan antar manusia dalam perspektif Islam memiliki pengaruh besar bagi orang yang menyampaikan dan orang yang mendengarkan. Karena itulah Allah mengutus Rasul-Nya untuk memberikan peringatan kepada umatnya $^{7}$ dan mendorong umatnya untuk saling mengingatkan. ${ }^{8}$

Karena muara semua tujuan komunikasi adalah saling mempengaruhi, maka membangun komunikasi yang bertujuan untuk menciptakan suasana yang sehat adalah bagian yang tidak terpisahkan dari Islam. . Pengaruh pesan tersebut tidak hanya sesaat, tetapi kadang-kadang kekal sepanjang hidup komunikan. Wahab bin Munabbih pernah berkata :

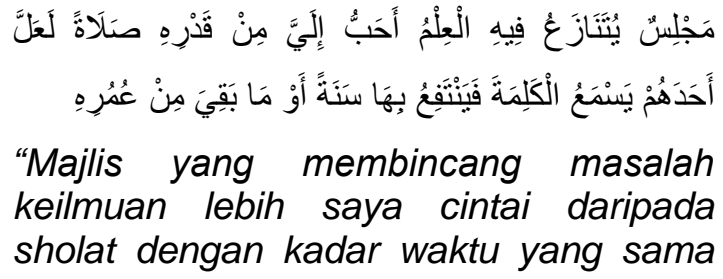

"Majlis yang membincang masalah keilmuan lebih saya cintai daripada sholat dengan kadar waktu yang sama

6 Stewart L.Tubbs-Sylvia Moss, Human Communication (edisi Indonesia), ( Bandung, PT.Remaja Rosdakarya, 2001), h.3

7 Dalam Surah al A'la ayat 9 Allah berfirman : (فذكر ) إن (1) dan dalam Surah Al Ghasyiah فذكر إنما أنت مذكر ، ) (ayat 21 dan 22 disebutkan :

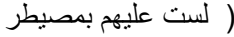

8 Allah berfirman dalam Surah Al Ashr ayat $3:$ : ) (الذين آمنو ا و عملو ا الصالحات وتو اصو ا بالحق وتو اصو ا بالصبر 
yang dihabiskan untuk kajian ilmu. Barangkali ada di antara mereka yang mendengar satu kata, lalu kata tersebut bermanfaat untuk dirinya selama setahun atau seumur hidupnya". 9

Dalil-dalil yang terdapat dalam al-

Quran dan Hadis memberikan informasi yang sangat kaya tentang pengaruh strategis komunikasi, di antaranya adalah :

1. Dapat mengubah pendapat orang lain.

Merubah pandangan orang lain bukanlah pekerjaan mudah, tetapi dengan terjadinya proses tukar-menukar pendapat, hal tersebut dapat dilakukan. Di antara kekuatan bahasa atau pesan itu adalah kemampuannya 'membius' lawan bicara.. Rasulullah SAW bersabda

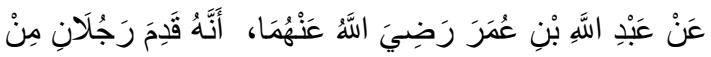

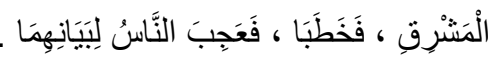

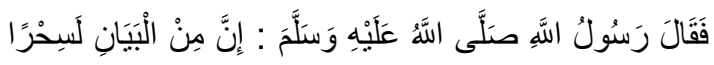

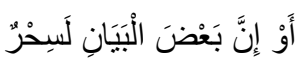

"Dari Abdullah bin Umar RA., telah datang dua orang dari Masyriq, lalu keduanya berpidato. Orang-orang terkagum-kagum dengan penjelasannya. Lalu Rasulullah SAW bersabda: "Sesungguhnya di antara pesan yang terucap itu adalah bius". 10

Menurut Ibnu Hajar, 'bayan' itu terbagi dua, pertama, penjelasan maksud yang sebenarnya; kedua, memperindah retorika sehingga hati para pendengar terpesona mendengarkannya. Seni menyampaikan pesan yang

\footnotetext{
9 HR. Darimi No. 327

10 HR. Bukhari, No. 4749, 5325, dan Muslim No. 1437
}

membuat orang terpesona disebut oleh Nabi sebagai sihir karena ia bisa mengalihkan perhatian pendengar kepada makna yang diinginkan oleh pembicara, meskipun keliru.

Jika pesan yang disampaikan membuat orang tertarik menerima pesan yang keliru, maka dia menjadi tercela. Rasulullah SAW bersabda :

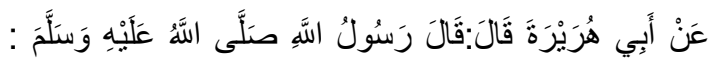

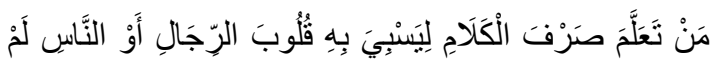

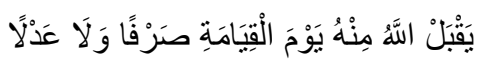

"Dari Abu Hurairah RA., Rasulullah SAW bersabda : "Barangsiapa mempelajari seni menyampaikan pesan untuk menawan hati-hati manusia, Allah tidak akan menerima segala tebusannya di hari kiamat". ${ }^{11}$

Tetapi, jika dia mampu menarik perhatian orang dengan tujuan menunjukkan jalan hidayah dan orang mendapatkan hidayah lewat perantaraannya maka perbuatan tersebut sangat terpuji. Rasulullah SAW bersabda :

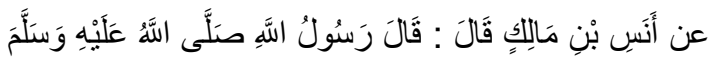

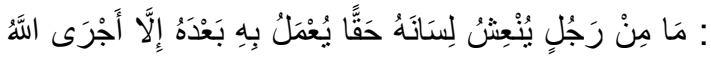

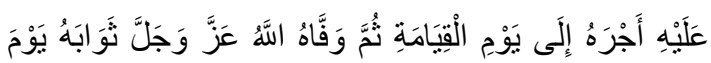
الْفِيَامَة

"Dari Anas bin Malik berkata, Rasulullah SAW bersabda : Tidak ada seorangpun yang mengefektifkan lisannya untuk kebenaran, lalu apa yang dia katakan diamalkan oleh orang setelahnya, kecuali Allah akan mengalirkan pahalanya sampai hari kiamat, kemudian Allah akan

${ }^{11}$ HR. Abu Daud No. 4353 
sempurnakan pahalanya pada hari kiamat". ${ }^{12}$

Apakah retorika itu mengajak manusia kepada yang baik atau yang buruk, tetapi keduanya memiliki titik temu, yaitu pada aspek pengaruhnya yang kuat.

Nabi Musa memahami betul pentingnya kefasihan lisan dalam upaya mempengaruhi Fir'aun. Nabi Musa yang mengenal peta kekuatan dan kelemahan dirinya mengatakan kepada Tuhannya bahwa dia memiliki kelemahan dalam hal mengungkapkan pesan. Karenanya Musa meminta kepada Allah dua hal : pertama, menghilangkan kekeluan lisannya; dan kedua, meminta kepada Allah agar menjadikan Harun sebagai pendampingnya, karena Harun memiliki kekuatan di bidang kefasihan. ${ }^{13}$

Untuk menundukkan Fir'aun, Allah memerintahkan Nabi Musa dan Nabi Harun untuk menyampaikan pesan dengan strategi 'qoulan layyinan.' Ungkapan Qaulan layyinan secara bahasa berarti ungkapan yang lemah lembut. Ungkapan ini terdapat dalam alQuran Surah Thāha ayat 44:, Allah swt berfirman: "Maka berbicaralah kamu berdua kepadanya dengan kata-kata yang lemah lembut, mudah-mudahan ia ingat atau takut."

\footnotetext{
12 HR. Ahmad No.13302

13 Hal ini tertuang dalam al-Quran Surat Thaha ayat 24 - 32 dan Surat al-Qashash ayat 34.
}

Di antara pendapat para ulama tentang makna qaulan layyinan adalah: ajarkan kepada Firaun kalimat syahadat, bahwa tiada ilah selain Allah, atau sampaikan kepadanya bahwa dia punya Tuhan dan tempat kembali, dan di hadapan dia ada surga dan ada neraka, atau panggil dia dengan panggilan kesayangannya, yakni Abi Murrah. ${ }^{14}$

\section{Berdasarkan pendapat para} ulama di atas, qaulan layyinan adalah upaya untuk berkomunikasi dengan orang lain dengan cara yang lunak, tidak memvonis, mengingatkan tentang sesuatu yang disepakati seperti kematian, dan memanggilnya dengan panggilan yang dia sukai.

Qaulan layyinan akan membuat hati yang keras bisa tadzakkur 'merenungkan kembali akan hakikat dirinya' serta 'yakhsya' menjadi takut akan Allah dan berbakti kepada-Nya.

Jika orang yang sombong dan durjana saja perlu dihadapi dengan kelembutan, maka orang yang kejahatannya di bawah itu atau orangorang baik yang terperosok ke lembah maksiat seharusnya diperlakukan lebih baik.

Selanjutnya kefasihan,ungkapan yang teratur, berjeda, dan diulang beberapa kali membuat pendengar

\footnotetext{
${ }^{14} \mathrm{Abu}$ al- Fida' Ismail bin Katsir, Tafsir al-Quran al'Adzim, (Al-Madinah al-Munawwarah: Maktabah al-Ulum wa al-Hikam, 1413-1993), juz 3, h.149.
} 
mampu mengikat makna dari pesan yang disampaikan. Ketika mendengar Abu Hurairah $^{15}$-sepeninggal Nabi SAWberbicara hampir tanpa nafas, A'isyah menegur sahabat tersebut dan berkata :

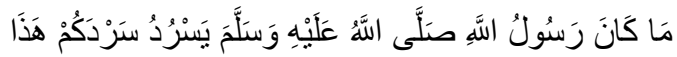

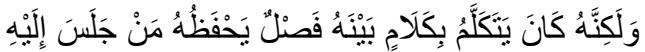

"Rasulullah SAW tidak pernah berbicara cepat seperti kalian, tetapi Beliau selalu berbicara dengan disertai jeda, sehingga orang yang mendengarnya dapat menghafalkan perkataan Beliau". ${ }^{16}$

2. Menjadi faktor yang menentukan baik buruknya manusia

Saat berinteraksi manusia hanya dihadapkan pada dua pilihan, mempengaruhi atau dipengaruhi. Untuk menghindari pengaruh negatif, sebaiknya kita tidak bermesraan dengan orangorang yang dapat merusak perilaku kita. Rasulullah mengingatkan kita tentang hubungan erat antara kebaikan atau kejahatan dengan hubungan komunikasi yang kita bangun.

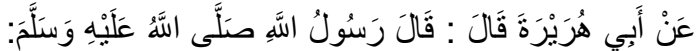

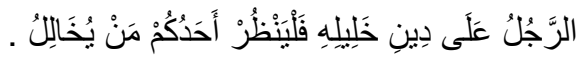

Dari Abu Hurairah, Rasulullah SAW bersabda : "Seseorang itu tergantung kepada agama teman dekatnya. Hendaklah seseorang memperhatikan dengan siapa dia berteman". 17

\footnotetext{
15 Nama Abu Hurairah disebut dalam riwayat Muslim No.4548

16 HR. Bukhari No.3303, Muslim No.4548, HR.Tirmidzi, No.3572. Dia berkata, hadits ini hasan shahih..

17 HR.Thirmidzi No.2300, Abu Dawud No. 4193, Ahmad, No. 7685, 8065. Thirmidzi berkata : hadits ini Hasan Gharib
}

Kata "khalil" mengandung makna persahabatan dan kasih sayang yang menembus ruang-ruang hati. ${ }^{18}$ Model persahabatan seperti ini tentunya bersumber dari komunikasi yang telah terbangun lama di antara dua sahabat tersebut, sehingga yang muncul adalah hubungan 'seia sekata'. Tarde menyebut fenomena seseorang dipengaruhi oleh perilaku orang lain yang berinteraksi sehari-hari dengan teori imitasi. ${ }^{19}$ Jika yang ditiru baik, seseorang diharapkan akan baik. Tapi jika yang ditiru adalah rusak, maka akan rusaklah sikap manusia.

3. Komunikasi yang baik dapat mendatangkan kenyamanan psikologis bagi komunikator dan sekaligus komunikan.

Seseorang yang mengungkapkan kata-kata yang baik akan membuat hatinya tenang. Itulah rahasia dari perintah Allah yang menganjurkan kita banyak mengucapkan dzikir. Allah berfirman :

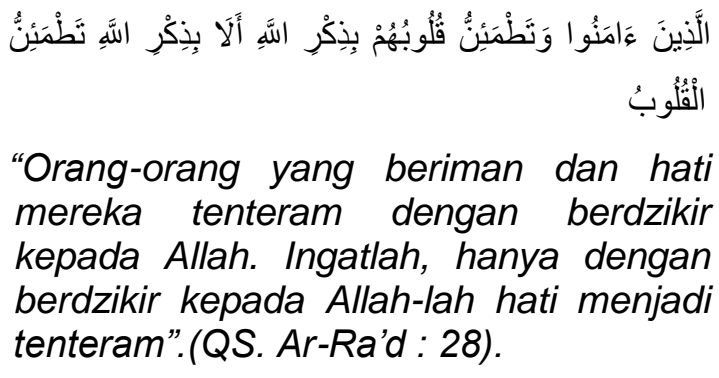$$
\text { الْقلُُوبُ }
$$

"Orang-orang yang beriman dan hati mereka tenteram dengan berdzikir kepada Allah. Ingatlah, hanya dengan berdzikir kepada Allah-lah hati menjadi tenteram".(QS. Ar-Ra'd : 28).

\footnotetext{
18 Ibrahim Mushtafa , al-Mu'jam al-Wasith, ( Istanbul, Al-Maktabah al-Islamiyyah, t.th), h.253

${ }^{19}$ Onong Uchjana Effendi, op.cit.,h.248
} 
Ketenangan tersebut tidak hanya

buat diri komunikator, tetapi juga berdampak baik kepada komunikan. Rasulullah mengajarkan tentang pentingnya membangun optimisme orang yang sedang terbaring sakit dengan kata-kata yang memberikan semangat hidup.

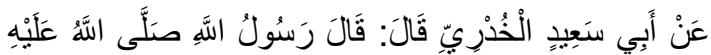

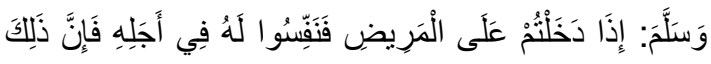

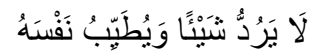

Dari Abi Sa'id al Khudri berkata, Rasulullah SAW bersabda : "Jika kamu menjenguk orang sakit, sampaikan kepadanya tentang ajal yang masih jauh, karena perkataan itu tidak akan merubah apa-apa, tetapi mendatangkan efek ketenangan bagi dirinya."

Menyampaikan kata-kata yang memberikan harapan kepada seseorang adalah lebih baik daripada kata-kata yang membuat orang pesimis. Di antara tujuan komunikasi adalah memberikan kenyamanan psikologis kepada orang yang mendengarkan.

4. Pesan yang diungkapkan dengan bahasa yang penuh optimistis membangkitkan semangat untuk melakukan perubahan

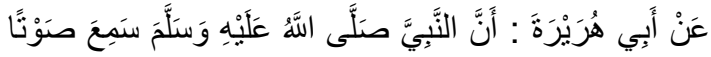

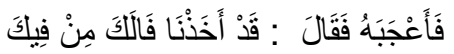

Dari Abu Hurairah, sesungguhnya Nabi SAW mendengarkan suara yang membuatnya terkagum-kagum, lalu berkata : Sungguh kami telah mengambil semangat optimismemu dari mulutmu. ${ }^{21}$

\footnotetext{
20 HR.Tirmidzi, No.2013. Dia berkata, hadits ini gharib

${ }^{21}$ HR Ahmad, No.8679, Abu Dawud, No.3416
}

Menyampaikan pesan dengan nada optimis adalah langkah awal menuju kemenangan. Optimisme yang dibangun oleh seseorang menyebabkannya bergairah untuk menggapainya. Nabi Muhammad selalu mendidik sahabatnya dengan bahasa optimis. Saat menggali parit sebagai strategi membendung serangan pihak lawan yang akan menyerang kota Madinah dalam perang Khandaq tahun ke-5 kenabian, kondisi logistik kaum muslimin sangat memprihatinkan. Kadang-kadang mereka hanya bertahan dengan beberapa biji kurma, sehingga ada di antara mereka yang harus menyandarkan batu ke perutnya karena kelaparan. ${ }^{22}$ Saat sahabat tidak bisa memecahkan batu, para sahabat meminta Rasul untuk memecahkannya. Rasulpun memukul batu itu dengan tiga kali pukulan dan beliau berhasil memecahkannya. Dalam pukulan pertama Rasulullah bertakbir, dan berkata : telah diberikan kepadaku kuncikunci kerajaan Syam. Demi Allah, sekarang aku sedang menyaksikan istana merah Syam yang indah itu. Dalam pukulan keduanya beliau bertakbir lagi dan berkata : telah diberikan kepadaku kunci-kunci kerajaan Persia. Demi Allah, aku sedang

\footnotetext{
22 Akram Dhiya' al-'Umari, Al-Sirah al-Nabawiyyah al-Shahihah, (Madinah, Maktabah al-Ulum wa al-Hikam, t.th), jilid 2,h.421
} 
menyaksikan Gedung Putih Madain. Saat melakukan pukulan ketiganya Rasulullahpun bertakbir dan berkata: demi Allah, telah diberikan kepadaku kunci-kunci kerajaan Yaman, dan saat ini aku sedang menyaksikan pintu-pintu gerbang Shan'a. ${ }^{23}$ Optimisme tinggi seperti ini membuat sahabat bekerja tanpa lelah dan dalam waktu singkat proyek penggalian parit yang cukup panjang ini berakhir.

Optimisme juga adalah langkah awal melangkah menuju Surga. Rasulullah mengatakan bahwa kalau seseorang berdoa meminta surga, jangan meminta surga yang sekedarnya, tapi mintalah surga yang paling mewah, yaitu Firdaus. ${ }^{24}$

5. Lisan lebih efektif daripada pedang

Lisan bisa membunuh karakter seseorang. Gara-gara fitnah yang dilancarkan oleh orang munafik di Madinah, Aisyah istri Rasulullah tercemar nama baiknya, Rasulullah yang biasanya sangat romantis berubah sikapnya, dan banyak sahabat yang termakan isu fitnah tersebut. Peristiwa itu membawa luka mendalam pada Aisyah sehingga dia kehabisan air mata untuk mengungkapkan

rasa

\footnotetext{
23 HR. Ahmad dan an-Nasa-i. Al Hafidz Ibnu Hajar mengatakan sanad hadits ini sanad dan berakhir pada Bara' bin 'Azib, salah seorang saksi mati dan pelaku sejarah perang Khandaq. (Fath alBari, 7/397)

24 HR.Bukhari, No.2581
}

kesedihannya. Itulah yang terjadi pada Aisyah pada peristiwa 'hadits al-ifki' ${ }^{25}$

Gara-gara lisan, suatu komunitas bisa hancur berantakan.

$$
\begin{aligned}
& \text { عَنْ عَبْدِ السَّهِ بْنِ عَمْرِو قَالَ:قَالَ رَسُولن السَّهِ صَلَّى السَّهُ عَلَيْهِ }
\end{aligned}
$$

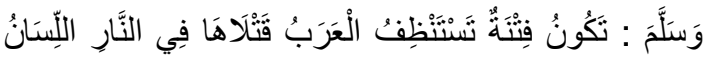

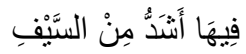

Dari Abdullah bin 'Amr berkata, Rasulullah SAW bersabda: Akan terjadi fitnah yang membuat Arab mati bergelimpangan. Lisan pada saat itu jauh lebih tajam daripada pedang.. ${ }^{26}$

\section{Kode Etik Menyampaikan dan Menerima Informasi}

Karena besarnya pengaruh informasi, maka Islam memberikan arahan agar orang yang terlibat dalam komunikasi, baik selaku penyedia informasi atau sebagai penerimanya, memperhatikan kode etik yang terkait dengan komunikasi.

Di antara kode etik itu adalah:

1. Lebih banyak mendengar daripada berbicara.

Allah sudah memberikan isyarat lewat penciptaan-Nya sikap yang harus di ambil manusia. Dia ciptakan pada manusia dua telinga dan satu mulut. Makna yang paling mudah ditangkap dari fakta ini adalah agar manusia

\footnotetext{
25 Kisah ini bisa dilihat pada Tafsir lbnu Katsir saat menafsirkan al-Quran, Surat An-Nur ayat 11 . Abu al Fida' Ismail bin Katsir al-Dimasyqi, Tafsi al-Quran al-Adzim, (Madinah, Maktabah al-Ulum wa al-Hikam. 1993), jilid 3, h.260

${ }^{26}$ HR.Tirmidzi, No. 2104, beliau berkata, hadits ini gharib
} 
diperintahkan untuk banyak mendengar dan tidak menyampaikan semua yang didengar.

Menceritakan kembali semua yang didengar adalah tanda kecerobohan seseorang. Tidak semua informasi yang sampai kepada seseorang dipahami secara benar, atau dipahami secara benar tetapi beritanya tidak benar, atau beritanya benar tetapi tidak layak dikonsumsi oleh publik. Menceritakan kembali semua yang didengar akan beresiko memiliki tingkat kesalahan yang banyak. Di dalam istilah agama disebut dengan dosa (itsm).

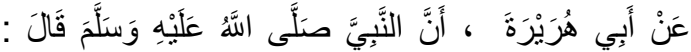

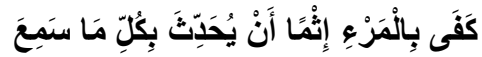

Dari Abu Hurairah, sesungguhnya Nabi SAW bersabda : "Cukuplah dosa bagi seseorang untuk menyampaikan semua yang dia dengar"27

2. Memelihara lisan, hanya berbicara yang baik-baik saja.

Lisan adalah di antara sarana yang berfungsi untuk menerjemahkan pesan-pesan simbolik dari keinginan yang terdapat di dalam hati. Lisan memiliki peran kunci dalam berkomunikasi, apakah membawa kita kepada kesuksesan atau kehancuran.

Kata kotor yang diucapkan lisan adalah cerminan dari jiwa yang kotor. Sedangkan jiwa yang bersih berdampak

27 HR.Abu Dawud, No. 4340 pada ucapan dan tingkah laku sehariharinya. Rasulullah SAW bersabda :

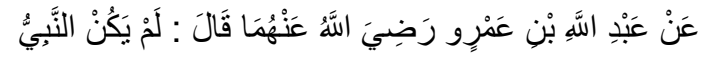

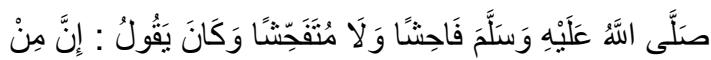

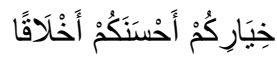

Dari Abdullah bin 'Amr RA berkata : Nabi tidak pernah mengucapkan kata-kata jorok dan tidak menyukai perkataan seperti itu, dan Beliau bersabda: "Sesungguhnya orang yang terbaik di antara kalian adalah yang paling baik akhlaknya". ${ }^{28}$

Perkataan yang kotor membuat suasana rusak dan dapat menghilangkan budaya rasa malu. Padahal kalau malu sudah hilang dari pribadi seseorang, dia ibarat orang yang kehilangan rem untuk mengendalikan dirinya. Rasulullah SAW bersabda :

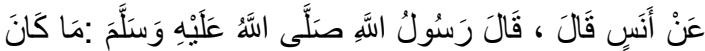

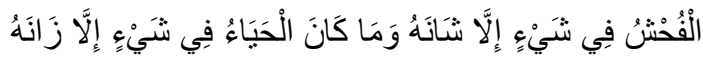
Dari Anas berkata, Rasulullah SAW bersabda : "Tidaklah hinggap perkataan yang tidak senonoh pada sesuatu kecuali akan membuat rusak suasana, dan tidaklah mampir rasa malu pada sesuatu kecuali akan memperindah suasana". 29

Sebaliknya, ungkapan yang ramah memiliki pengaruh terhadap kelembutan jiwa, sedangkan ungkapan yang kasar membuat jiwa tidak sensitif terhadap kekerasan. Jiwa yang kasar membuat orang menjaga jarak dari dirinya. Di antara rahasia kesuksesan

\footnotetext{
28 HR.Bukhari No.3295,3476, 5569, 5575 ; Muslim, No.4285

29 HR.Thirmidzi, No.1897; Ibnu Majah, No. 4175. Abu Isa berkata: hadits ini statusnya hasan gharib
} 
Nabi Muhammad dalam misi dakwahnya adalah kelembutan hati. Allah berfirman :

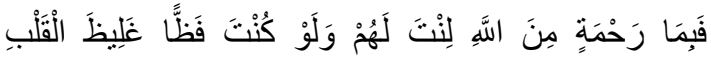

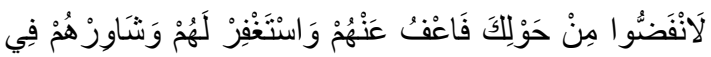

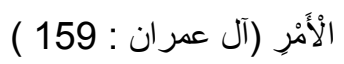

"Maka disebabkan rahmat dari Allah-lah kamu berlaku lemah lembut terhadap mereka. Sekiranya kamu bersikap keras lagi berhati kasar, tentulah mereka menjauhkan diri dari sekelilingmu. Karena itu maafkanlah mereka, mohonkanlah ampun bagi mereka, dan bermusyawarahlah kamu dalam urusan itu" (QS.Ali Imran : 159)

3. Tidak berbicara kecuali dengan data yang valid

Berbicara dengan data dan informasi akurat adalah salah satu ciri pribadi berkualitas. Selain menambah kredibilitas, informasi yang akurat menghindarkan kita jatuh kepada kesalahan yang berujung kepada penyesalan. Allah berfirman :

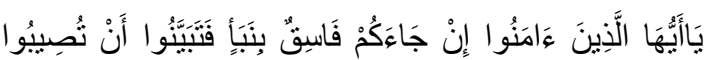

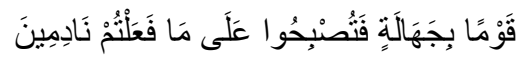

"Hai orang-orang yang beriman, jika datang kepadamu orang fasik membawa suatu berita, maka periksalah dengan teliti, agar kamu tidak menimpakan musibah kepada suatu kaum tanpa mengetahui keadaannya yang menyebabkan kamu menyesal atas perbuatanmu itu". (QS.Al Hujurat : 6)

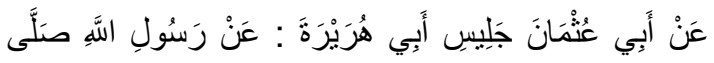

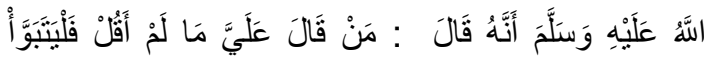

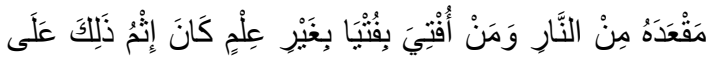

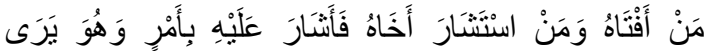

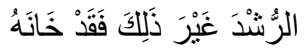

Dari Abu Utsman, teman duduk Abu Hurairah, Rasulullah SAW bersabda: "Barangsiapa yang berbicara tentangku padahal aku tidak pernah mengatakannya, maka tempatnya nanti adalah neraka. Barangsiapa diberi suatu fatwa tanpa landasan ilmu, maka dosanya ditimpakan kepada yang memberi fatwa. Barangsiapa yang meminta pendapat kepada saudaranya, lalu dia memberikan pendapatnya yang dia pandang kebenaran bukan pada pendapat yang dia utarakan kepada saudaranya, maka dia dianggap telah mengkhianati saudaranya"30

4. Memegang prinsip perimbangan dalam menyerap informasi

Informasi yang seimbang akan membuat keputusan menjadi akurat. Prinsip perimbangan dalam menyerap informasi sebelum memberikan sikap adalah keharusan.

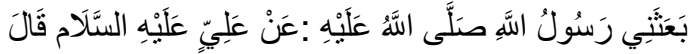

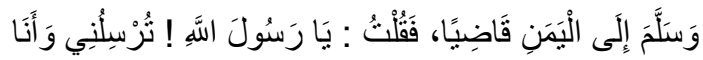

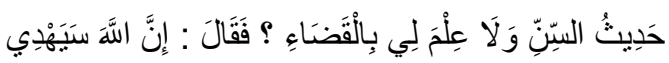

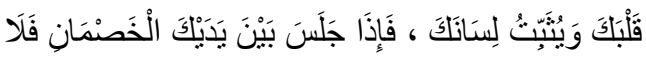

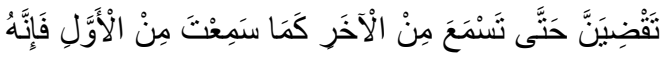

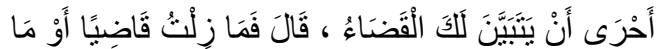

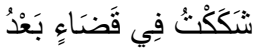

Dari Ali alaihissalam berkata, Rasulullah SAW mengutusku ke Yaman sebagai qadhi. Aku berkata, Ya Rasulullah, Engkau mengutus aku, padahal aku masih muda belia dan aku belum mengetahui ilmu tentang masalah qadha'? Beliau menjawab: sesungguhnya Allah akan memberikan hidayah ke hatimu dan menetapkan lisanmu. Apabila dua orang yang sedang bertikai menghadapmu, janganlah

${ }^{30}$ HR.Ahmad, No.8421 
Engkau memutuskan perkara sehingga kamu dapat menyerap informasi ada kedua belah pihak, karena hal tersebut dapat memudahkanmu menetapkan keputusan. $^{31}$

5. Tidak menyebarkan berita bohong

Bohong berarti memanipulasi informasi sehingga pesan tidak sampai sebagaimana mestinya.

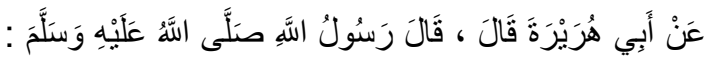

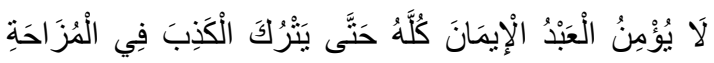

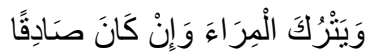

Dari Abu Hurairah berkata, Rasulullah SAW bersabda : "Tidak sempurna iman seseorang sehingga meninggalkan dusta meskipun saat canda, dan meninggalkan pertengkaran meskipun berada pada pihak yang benar ${ }^{32}$

Enam kode etik di atas merupakan unsur terpenting yang harus terpenuhi dalam menjaga kualitas berkomunikasi menurut ajaran Islam. Dengan memperhatikan kode etik seperti ini diharapkan komunikasi yang dibangun oleh manusia sehat dan berkualitas.

\section{Penutup}

Memahami besarnya pengaruh komunikasi dalam kehidupan manusia menjadikan manusia harus memperhatikan secara seksama bagaimana seharusnya berkomunikasi. Menerapkan kode etik berkomunikasi merupakan uapaya agar manusia

${ }^{31}$ HR. Abu Dawud, No.3111

32 HR.Ahmad, No.8276, 4811 berkomunikasi secara sehat dan berkualitas, serta menghindari rusaknya suasana dan hubungan antar manusia.

\section{E. Daftar Pustaka}

Al Qur'an al Karim dan Terjemah

Al-Bukhari al-Ju'fi, Muhammad bin Ismail Abu Abdillah, Shahih alBukhari, Dōr Thũq al-Najāh, 1422

Devito, Joseph A., Human Communication, The Basic Course (New York, HarperCollins Publishers, 1991)

Ibnu Katsir al-Dimasyqi, Abu al Fida' Ismail, Tafsir al-Quran al-Adzim, (Madinah, Maktabah al-Ulum wa al-Hikam. 1993)

Mushtafa, Ibrahim, al-Mu'jam al-Wasith, ( Istanbul, Al-Maktabah alIslamiyyah, t.th)

Al-Naisābũri, Muslim bin al-Hajjōj Abu alHasan al-Qusyairi, Shahih Muslim, Beirut: Dōr Ihyō' al-Turōts al-'Arabi, t.th.

Al-Nasâ-i, Abu Abdirrahman Ahmad bin Syu'aib bin Ali al-Khurasani, Sunan al-Nasâ-i, Halab: Maktab alMathbû'ât al-Islâmiyyah, 14061986, Cet.1.

Onong Uchjana Effendi, IImu, Teori dan Filsafat Komunikasi (Jakarta, PT.Citra Aditya Bakti, 2003) 
Al-Sijistâni, Abu Daud Sulaiman bin alAsy'ats bin Ishaq bin Basyir bin Syaddad bin 'Amr al-Azdi, Beirut: al-Maktabah al-'Ashriyyah, t.th.

Al-Shaibāni, Ahmad bin Hanbal, AlMusnad, (Beirut: al-Maktab alIslāmi, 1413), cet.1.

Al-Tirmidzi, Muhammad bin Isa bin Saurah bin Musa bin Dhahhāk, Abu Isa, Sunan al-Tirmidzi, Beirut:
Dōr al-Kutub al-Ilmiyyah, 14081987.

Stewart L.Tubbs-Sylvia Moss, Human Communication (edisi Indonesia), ( Bandung, PT.Remaja Rosdakarya, 2001)

al-'Umari Akram Dhiya', Al-Sirah alNabawiyyah al-Shahihah, (Madinah, Maktabah al-Ulum wa al-Hikam, t.th) 